\title{
Reintroducing the Current Insights Feature
}

Julia Gouvea** and Sarah L. Eddy ${ }^{*}$

'Tufts University, Medford, MA 02155; ₹Florida International University, Miami, FL 33199
A s new coeditors of the Current Insights feature, our goal is to draw on our different backgrounds, expertise, and scopes of interest beyond biology education to bring a broad range of articles to CBE-Life Sciences Education (LSE) readers. In this, our first issue, we have each chosen to highlight two recent articles outside LSE that have impacted our own teaching and/or research.

Gouvea: In both my teaching and research I often wonder about the lasting impacts of learning experiences on students-in both the short and long term. The two papers I have chosen to highlight address this question by comparing the aftereffects of contrasting learning experiences. The first study explores the short-term impact of a change in the structure of a single physics activity on posttest performance. The second examines the long-term effects of two very different mathematics curricula on students' future lives. Although they differ in scope and scale, each study provides evidence that giving students more intellectual responsibility and freedom has positive effects on learning - in the first instance immediately and in the other nearly a decade later.

Shemwell, J. T., Chase, C. C., \& Schwartz, D. L. (2015). Seeking the general explanation: A test of inductive activities for learning and transfer. Journal of Research in Science Teaching, 52(1), 58-83. http://doi.org/10.1002/tea.21185

Shemwell and colleagues examined the impacts of a relatively small change in the design of an activity on university students' learning of Faraday's law, which relates changes in a magnetic field to changes in electric current. In each version of the activity, students used a computer simulation to examine three scenarios involving a moving magnet and a coil of wire linked to a bulb to visualize changes in current. One version of the activity asked them to reason deductively-making predictions, making observations, and generating explanations for each scenario. The other version asked students to inductively generate a single explanation that could account for all three cases. Students who completed the inductive version scored roughly twice as high on a posttest that included novel magnet and coil problems.

Shemwell and coworkers reasoned that the difference could be explained by students focusing on deeper causal features in the inductive condition. Students in the deductive condition could treat each example separately, while students in the inductive condition were prompted to generate an explanation that required looking for more general principles. Indeed, students in the inductive condition were more likely to refer to a general principle in their written explanations, and references to more general principles were correlated with higher posttest scores. Students in the deductive condition were more likely to make reference to specific, observable, but nonexplanatory features rather than deep explanatory principles in their explanations.

These results demonstrate that students in a university physics course "do not spontaneously search for a general explanation[s]" but can do so if they are asked, suggesting that students do have the ability to construct deep causal explanations but may not understand that doing so is desired or expected of them. Shemwell and colleagues point to the need to help students cultivate "inductive scientific dispositions." One way
CBE Life Sci Educ June 1, 2017 16:fe3 DOI:10.1187/cbe.17-03-0053

This feature is designed to point CBE-Life Sciences Education readers to current or noteworthy articles for life science educators and education researchers. We invite readers to suggest current themes or articles of interest in life science education as well as influential papers published in the more distant past or in the broader field of education research to be featured in Current Insights. Please send any suggestions to Julia.Gouvea@tufts.edu.

*Address correspondence to: Julia Gouvea (Julia. Gouvea(atufts.edu).

(C) 2017 J. Gouvea and S. L. Eddy. CBE-Life Sciences Education @ 2017 The American Society for Cell Biology. This article is distributed by The American Society for Cell Biology under license from the author(s). It is available to the public under an Attribution-Noncommercial-Share Alike 3.0 Unported Creative Commons License (http://creativecommons.org/licenses/ by-nc-sa/3.0).

"ASCB®" and "The American Society for Cell Biology $\AA^{\circ}$ are registered trademarks of The American Society for Cell Biology. 
to do so is to ask students to engage in synthetic induction more often-have students construct general explanations for themselves rather than primarily learn and apply explanations provided by instructors.

Boaler, J., \& Selling, S. K. (2017). Psychological imprisonment or intellectual freedom? A longitudinal study of contrasting school mathematics approaches and their impact on adults' lives. Journal for Research in Mathematics Education, 48(1), 78-105. http://doi.org/10.5951/jresematheduc .48.1.0078

In this paper, Boaler and Selling examined the long-term effects of different approaches to teaching, and hence two different experiences of learning mathematics, on students' adult lives. More than a decade ago, Boaler conducted a 3-year comparative study of secondary students at two schools. At Amber Hill, mathematics was taught in a traditional manner, using textbooks and lectures. Students at this school were "tracked" into separate classes by performance. At Phoenix Park, students worked in heterogeneous groups on open-ended mathematics projects. In the original study, Boaler found differences between the two cohorts (matched in terms of social class and prior achievement), with Phoenix Park students demonstrating deeper understanding of mathematical concepts, higher achievement scores, and an improved sense of themselves as capable and flexible mathematical problem solvers. Amber Hill students, in contrast, deidentified with mathematics, describing it as boring and irrelevant.

In the 2017 follow-up study, Boaler and Selling contacted students from the original study 8 years later. Using survey and interview data, they found evidence that the differences in how each cohort experienced mathematics learning in school impacted their adult lives, both professionally and in their identification with and understanding of mathematics. The first major finding was that adults who had attended Phoenix Park, the project-based school, had jobs higher on the socioeconomic scale than respondents from Amber Hill, the traditional school. The second major finding related to how members of each cohort described their mathematical affinities and identities. Adults from the Phoenix Park cohort recalled their math learning experiences as open-ended and supportive of their intellectual freedom. They described themselves as flexible and persistent in their approaches to math problem solving in their adult lives and universally reported that the math they had learned in school was useful to them in their daily lives. In stark contrast, adults from the Amber Hill cohort recalled their school mathematics experiences with regret and reported that math was not useful in their daily lives. Former Amber Hill students did not speak of persisting in math problem solving, but instead described relying on others with greater math expertise for help. This work makes it clear that open-ended project-based learning can have both short- and long-term educational impacts.

As a biology educator and education researcher, these two articles together have me thinking across scales. How could small changes at the level of how tasks are structured add up to a different experience of learning biology overall? And how could such experiences of identifying and engaging deeply with biology, or with science more generally, end up making a difference in a student's life?

Eddy: In my own teaching and research, I consider how who we are impacts our experiences in the classroom both as students and teachers. Classroom experiences include aspects like pedagogical strategies, the social climate, or even our experiences of the class topics. The two papers I have chosen to highlight explore this theme in different ways. The first looks at how stereotypes about gender impact who earns graduate degrees in many disciplines. The second measures the importance of the teacher-student relationship on performance. Although neither study was conducted in a classroom context, they both suggest practices that may help reduce disparities between different student groups.

Leslie, S.-J., Cimplian, A., Meyer, M., \& Freeland, E. (2015). Expectations of brilliance underlie gender distributions across academic disciplines. Science, 347(6219), 262-265. http://science.sciencemag.org/content/347/6219/262

Understanding why women are underrepresented in many science, technology, engineering, and mathematics (STEM) fields is a hot research topic, but these research efforts do not often consider evidence from fields outside STEM. Leslie and colleagues (2015) looked across STEM, the social sciences, and the humanities to understand women's underrepresentation in divergent fields like physics, math, music composition, and philosophy. Although many researchers focus on gender-based stereotypes about who can be a scientist, Leslie and coworkers focused on stereotypes that run even deeper: stereotypes around intelligence and who can be "brilliant." The authors predicted that women will be underrepresented in any field, whether it is STEM or not, when the field is perceived to require brilliance for success. This prediction implies female underrepresentation is not just a STEM problem but a problem across many fields.

To test this hypothesis, Leslie and coworkers surveyed faculty, postdoctoral scholars, and graduate students. Participants reported on what it took to be successful in their own fields on a spectrum ranging from hard work to innate brilliance. The authors referred to this spectrum as the variable "ability beliefs." Leslie and colleagues ultimately focused on fields in which they had at least 20 respondents, which included nine social sciences, nine humanities, and 12 STEM disciplines. They also collected data from the National Science Foundation Survey of Earned Doctorates on the number of female PhDs awarded in 2011 in each discipline.

Using a model-building process that involved adding one variable at a time to an initial model, Leslie and colleagues discovered that both field (STEM vs. non-STEM) and ability beliefs significantly predicted the percent of PhDs earned by women. The predictive power of the model doubled when both ability beliefs and field (STEM or not) were included, relative to the model with just field (an $R^{2}$ increase from 0.25 to 0.54 ). Together, these results imply that ability beliefs and field independently contribute to the pattern of PhDs earned by women. Overall, fields in which success was perceived to be based more on hard work, such as sociology, anthropology, and molecular biology, had a larger proportion of PhDs earned by women than fields that were perceived to require brilliance, such as math and philosophy. Within these perception categories (requiring 
brilliance or not), STEM disciplines always had a lower proportion of women earning PhDs. Interestingly, ability beliefs also predict the representation of Black $\mathrm{PhD}$ students across fields but not the representation of Asian-American $\mathrm{PhD}$ students.

This work yields insight into one source of variation in female representation across STEM fields. In biology, a field predominantly female at the undergraduate level and with parity at the graduate level, practitioners generally believe that hard work plays a larger part in success than do practitioners in fields like math and physics. Thus, deliberately promoting the perception that hard work can lead to success in any field may be important for encouraging the persistence of our female students.

McClain, S., \& Cokley, K. (2017). Academic disidentification in Black college students: The role of teacher trust and gender. Cultural Diversity and Ethnic Minority Psychology, 23(1), 125-133. http://psycnet.apa.org/journals/cdp/ 23/1/125/

The influence of the instructor on students beyond the instructor's choice of pedagogical methods is an area only beginning to be explored in biology education (cf., Seidel et al., 2015). Evidence from the broader education and psychology literature suggests aspects of the student-teacher relationship can be predictors of persistence and achievement across many contexts and student groups (Ellis, 2000; Good et al., 2008, 2012). One aspect of that relationship is "instructor trust," meaning students' trust toward their instructors. McClain and Cokley (2017) explore how instructor trust is particularly potent for predicting Black male achievement in college.

In this study, McClain and Cokley recruited a stratified sample of 319 Black college students with approximately equal numbers of participants in their first, second, third, and fourth years of study. As part of a larger study on academic disidentification in college, students completed a survey related to their academic self-concept (i.e., their views of their own academic abilities), instructor trust, college grade point average (GPA), age, and gender. Researchers explored the influence all these variables had on one another and on the outcome variable, college GPA, using path analysis, an extension of multiple regressions that allows researchers to model the relationships between multiple variables. Instructor trust had a significant, positive relationship with GPA for both males and females, but the effect size for instructor trust was twice as large for males. This implies that the extent to which Black male students trust their instructors has a larger effect on their grades than the effect observed for Black female students. In addition, instructor trust seemed to degrade with age for Black males (but not females), implying experiences with instructors over the course of college were leading to less instructor trust in these male students.

These two articles are not testing classroom interventions. Nevertheless, I believe that, as instructors, we can learn from them. Together, they suggest that deliberate consideration of how we interact with our students may be a critical step for increasing their persistence and achievement. Specifically, the results of the first article suggest it may be important to emphasize success in class or in the major derives from hard work rather than intelligence. From the second article, we see that building relationships with our students based on mutual trust can influence their success. These practices are perhaps most critical for the success of our students from historically underrepresented groups.

URLs are provided for the abstracts or full text of articles.

\section{REFERENCES}

Ellis, K. (2000). Perceived teacher confirmation. Human Communication Research, 26(2), 264-291

Good, C., Aronson, J., \& Harder, J. A. (2008). Problems in the pipeline: Stereotype threat and women's achievement in high-level math courses Journal of Applied Developmental Psychology, 29(1), 17-28. http://doi .org/10.1016/j.appdev.2007.10.004

Good, C., Rattan, A., \& Dweck, C. S. (2012). Why do women opt out? Sense of belonging and women's representation in mathematics. Journal of Personality and Social Psychology, 102(4), 700-717. http://doi.org/ 10.1037/a0026659

Seidel, S. B., Reggi, A. L., Schinske, J. N., Burrus, L. W., \& Tanner, K. D. (2015). Beyond the biology: A systematic investigation of noncontent instructor talk in an introductory biology course. CBE-Life Sciences Education 14(4), ar43. 